Descent of Man

from a Correspondent

THE hundredth anniversary of the publication of Darwin's The Descent of Man set the theme for the symposium for the study of human biology held on November 19 at the Hospital for Sick Children, London. Professor J. S. Weiner (London School of Hygiene and Tropical Medicine), in a retrospective book review of Darwin's second major work, showed Darwin's remarkable foresight in predicting many features of human evolution which have subsequently been verified. Darwin's suggestion that man arose from a tropical African ape has found firm support not only in the fossil record but also in the more esoteric fields of molecular and biochemical investigations.

Dr D. Ferembach (University of Paris) was unable to attend, but his contribution, which suggested that in man and certain animals bone growth and bone morphology can be affected by dietary and caloric deficiencies during crucial growth periods, was read for him. Dr Ferembach questioned whether these effects may not have influenced morphological differences in living human groups. Dr C. Oxnard (University of Chicago), in a largely theoretical paper, discussed new analytical tools for the investigation of skeletal form. Medial axis transformation and Fourier optics were among the techniques he described as "optical dissection". Dr $\mathrm{H}$. Preuschoft (University of Tübingen), in a biomechanical investigation of certain East African fossil primates, suggested that "Proconsul", an important Miocene form, was strictly quadrupedal with no locomotor specializations for arboreal life.

Dr G. Olivier (University of Paris), in a restatement of the concepts of nineteenth century French anthropology, discussed the relationship between "hominization" and brain development as reflected in cranial capacity. Dr J. Musgrave (University of Bristol), using the results of a multivariate analysis of the hand of Neanderthal man and certain Upper Palaeolithic Homo sapiens, suggested that the two groups showed important anatomical differences in hand structure (see Nature, 233, 538 ; 1971). He further suggested that the Neanderthal hand, with its wide hand and short, broad phalanges, may have been cold adapted.

Dr M. H. Day (Middlesex Hospital Medical School) presented a discussion of Middle Pleistocene femora including the recently published Homo erectus femur from Olduvai Gorge (Nature, 232, 383 ; 1971). The great similarity between Olduvai Hominid 28 and the Peking femora has thrown further doubt on the provenance and relationships of the "Pithecanthropus erectus I" femur from Java. This specimen, which is stratigraphically associated with the Homo erectus skull cap from Trinil, has long been thought to show essentially modern morphology. Dr Day further suggested that the "Pithecanthropus erectus VI" femur, probably from Kedung Brubus, is not hominid at all and is possibly carnivore. Miss $\mathrm{T}$. Molleson (British Museum (Natural History)) discussed a variety of analytical and relative dating techniques used on the Javan femora in an attempt to define more clearly their provenance and date. The tests, using fluorine, uranium and nitrogen levels, have all been inconclusive as far as dating is concerned.

Undoubtedly the most important occasion of the day was the presentation by Mme and Dr Henri de Lumley (Marseilles University) of the new Arago material. In an almost unprecedented gesture, the participants in the symposium were able to examine the original specimens. The Arago Cave is situated in the south-eastern French
Pyrenees near the town of Tautavel. In a Tayacian level, dated through its geology and fauna to the earliest Riss (about 200,000 BP), a partial skull with a complete face and two mandibles have been found. The parietals and occiput of the skull are missing and an apparent stone tool remains fixed by matrix within the skull cavity; the face shows only slight damage and distortion. This skull is of great importance because only two other faces of Middle Pleistocene times are known ; one, Steinheim, is badly distorted and today, thirty-eight years after its discovery, it remains unprepared and inadequately described, and the second, "Pithecanthropus VIII" from Java, has only recently been reported and is so far incompletely prepared and described (S. Sartono, Proc. Ned. Akad. Wet., Ser. B, No. 2 ; 1971). At present it is obviously impossible to discuss the affinities of the Arago material. Its attribution, by the de Lumleys, to a "preNeanderthal" group is attractive at this stage in that the term reflects what is quite possibly its transitional nature.

\title{
Subsolidus Reduction of Lunar Spinels
}

A FEATURE of lunar rocks that sets them apart from their terrestrial equivalents is that they crystallized under extremely low partial pressures of oxygen. This has resulted in the virtual absence of ferric iron and in the widespread occurrence of troilite $(\mathrm{FeS})$ and metallic iron. A less obvious consequence now seems to be the reduction suffered by certain spinels after crystallization. Compositional variations in lunar spinels were recently discussed by $\mathrm{S}$. E. Haggerty in Nature Physical Science (233, 156; 1971) and in a communication in next Monday's issue he enlarges on this aspect.

Apart from a small isolated group of chromian pleonasts, all lunar spinels so far described belong to a series extending, with decreasing titanium content, from ulvospinel $\left(\mathrm{Fe}_{2} \mathrm{TiO}_{4}\right)$ towards chromite $\left(\mathrm{FeCr}_{2} \mathrm{O}_{4}\right)$; in addition, there is some substitution of $\mathrm{Mg}$ for $\mathrm{Fe}$ and of $\mathrm{Al}$ for $\mathrm{Cr}$. Re-examination of Apollo 12 material and a study of samples from Apollo 14 and 15 show the widespread occurrence of spinel-ilmenite-iron intergrowths. The ilmenite $\left(\mathrm{FeTiO}_{3}\right)$ forms lamellae along octahedral planes in the spinel and is accompanied by blebs of free iron.

Haggerty interprets the intergrowths not as true ex-solution effects, which they resemble, but as subsolidus reduction. Not all spinels in the series exhibit these intergrowths but only those, in any one sample, towards the ulvospinel end-as revealed by probe analysis. Examples are found further towards the chromite end in samples from Apollo 14 than in those from Apollo 15 or 12 , and further still in fragments of crystalline rocks from breccias than in unfragmented rocks. The subsolidus reduction of the spinel meant that it became increasingly enriched in the chromite end-member as $\mathrm{Fe}$ and $\mathrm{Ti}$ were removed to form more and more metallic iron and ilmenite.

Consideration of available thermodynamic data allows the oxygen fugacity to be plotted against temperature for the dissociation of the pure end-members ulvospinel, ilmenite, hercynite $\left(\mathrm{FeAl}_{2} \mathrm{O}_{4}\right)$ and chromite, and shows that of these minerals chromite is the most stable, ulvospinel the least. Ulvospinel can dissociate either partially to ilmenite and iron, or completely to rutile and iron. The fact that only partial dissociation is observed would seem to set close limits on the fugacity/temperature conditions. In one sample examined, the decomposition of a fayalitic olivine $\left(\mathrm{Fe}_{2} \mathrm{SiO}_{4}\right)$ to symplectic metallic iron and cristobalite provides confirmation of a very low oxygen fugacity, as the theoretical dissociation curve lies between those for the partial and complete dissociation of ulvospinel.

Haggerty holds that the decomposition observed indicates lower oxygen fugacities than those prevailing during crystallization. The reduction may have occurred during initial deuteric cooling, but the fact that the breccias are more intensely reduced than the crystalline rocks suggests that it may be related to contact with meteoritic iron vaporized during impact events. 